\title{
Los géneros periodísticos de opinión y los valores ${ }^{1}$
}

\author{
Gilberto MAGAÑA HERNÁNDEZ \\ Universidad de Guadalajara (México) \\ gilbertomagana@hotmail.com
}

Recibido: 14 de septiembre de 2014

Aceptado: 2 de marzo de 2015

\section{Resumen}

Este ensayo reflexiona sobre la necesidad del periodismo de opinión para "argumentar" con libertad y generar adhesión en ámbitos geopolíticos hispanohablantes. A partir de las conclusiones de un estudio sugiere que sea mediante programas de investigación y docencia con fundamentos éticos, como se consoliden los aportes de esos géneros peculiares del periodismo, y en cierto punto de una crisis sistémica.

Palabras clave: Persuasión, violencia, deóntica, libertad, internet.

\section{Opinion Journalism Genres and Values}

\begin{abstract}
This essay reflects about the Opinion Journalism ability to free argue and get adherence in Spanish speaking geopolitical contexts. Starting from the conclusions of a relevant study, it suggests that the way to consolidate the achievements in those peculiar genres of Journalism on a systemic crisis certain point, is by ethically based research and teaching programs.

Keywords: Persuasion, violence, deontic, freedom, internet.

\section{Referencia normalizada}

MAGAÑA HERNÁNDEZ, Gilberto (2015): "Los géneros periodísticos de opinión y los valores". Estudios sobre el Mensaje Periodístico. Vol. 21, Núm. 2 (julio-diciembre), págs.: 1099-1110. Madrid, Servicio de Publicaciones de la Universidad Complutense.
\end{abstract}

Sumario: 1. Presentación. 2. Su pertinencia frente a la violencia como factor de actualidad. 3. La argumentación como acto deóntico de sentido. 4. Crisis y oportunidad en el modelo hegemónico mexicano de comunicación periodística. 5. Conclusiones. 6. Referencias bibliográficas.

\section{Presentación}

Las prácticas para delimitar y desarrollar el ámbito de investigación significativo de los procesos y ciclos de comunicación periodística, han llegado a ser una urgencia, además de insustituible afán para académicos. Dicho así, en un campo profesional cuya permanente relación con la credibilidad supone esfuerzos morales extraordinarios, es para pensar en ampliar el alcance de estudios sobre textos y contextos; así como aportar evidencias, particularmente de las nuevas estructuras y formas de presentación de los géneros, secciones y discursos de opinión periodística.

Aunque de estos últimos se repite que históricamente han cumplido una función "cívica", parece insuficiente lo que actual y empíricamente se ha logrado, sobre todo cuando se han resignificado en el periodismo con la evolución de internet. Por ello aquí se les considera en su condición paradójica: un reto grande académicamente hablando.

1 Este artículo es fruto del proyecto "Alzando la voz. El pluralismo de opiniones y la información en una muestra de la prensa de Jalisco" (responsable: Dr. Francisco Aceves González), adscrito a la Maestría en Comunicación (Departamento de Estudios de la Comunicación Social, del Centro Universitario de Ciencias Sociales y Humanidades de la Universidad de Guadalajara, México), financiado por CONACyT. 


\section{Su pertinencia frente a la violencia como factor de actualidad}

La prensa ha sido transformada, en tanto herramienta social de análisis, opinión, e información, drástica y casi cotidianamente por la "guerra contra las drogas", acontecida en el tramo continental de América entre Colombia y Alaska ${ }^{2}$. Casi 623 millones de personas -más del $8.5 \%$ de la población mundial- se han visto afectadas por dicho conflicto.

Se cuenta ya con estudios que identifican y analizan textos periodísticos de opinión implicados en el tratamiento o cobertura de la "guerra contra las drogas" -o "el narcotráfico"-, así como con algunos relativos a las actividades profesionales de información sobre la violencia asociada a ello. Sobre lo primero es el caso de una muestra de prensa generalista de gran difusión, impresa y de circulación en España entre 2008 y 2010 (Magaña, 2013). En ella se señalan relaciones entre el carácter autoral mostrado por periodistas y colaboradore(a)s, ciertos criterios de autorregulación de las cabeceras, el empleo de recursos como el morbo sensacionalista o la participación crítica de los lectores.

Así por ejemplo, de dicha investigación resulta que la imagen de México como país "fiable" pasó, en muy pocos días, a la de Estado "fallido" en determinados relatos de opinión: columnas y editoriales, principalmente ${ }^{3}$. Si la violencia generada por el combate al narcotráfico y "la delincuencia organizada", era un tema secundario en las agendas informativas, según la versión del entonces presidente mexicano Felipe Calderón (y la mayoría de la prensa estudiada), al cabo de pocas semanas y coincidiendo con el brote de la epidemia de gripe A-H1N1, aquélla pasó a transformar, tanto el carácter de relatos de opinión, como la jerarquía de la información sobre México, las agendas mismas y los tipos de cobertura.

Por otra parte, se ha establecido con rigor que la impunidad y violencia preponderantes en México durante los años 2007 a 2014, han tenido consecuencias funestas para la prensa en estados como: Veracruz, Sinaloa, Michoacán o Tamaulipas. No obstante, en ciudades fronterizas como Tijuana o Juárez -en los estados de Baja California y Chihuahua- la historia es aún más larga, pues el periodismo ha mantenido una cierta continuidad, pasando por el reclamo ${ }^{4}$, y aun permaneciendo al borde de la extinción total. Esta probable dicotomía tendría que relacionarse con los estudios empíricos ya existentes, para que quede mostrada la gravedad de los atentados que sufren los comunicadores o los medios en sus coberturas, en lo general, o en aspectos puntuales, que preocupan mucho por sus regularidades tempo-espaciales. Así mismo, de los nuevos formatos de la información que -aún sin llegar a formalizarse en un perio-

2 Con datos de http://populationmatters.org/ y Wikipedia.

3 Véanse: "Un gran aliado de España" (ABC, editorial 2\%/3, j12/06/2008, p.4, en: http://www.abc.es/hemeroteca/historico-12-06-2008/abc/Opinion/un-gran-aliado-deespa\%F1a_1641928303694.html, recuperado el 21 de febrero de 2014; y "México busca fondos" (El Pais, editorial 2\%/2, d15/06/2008, p.34), en: http://elpais.com/diario/2008/06/15/opinion/1213480803_850215.html, recuperado el 21 de febrero de 2014; "México, la otra epidemia" (La Vangüardia, editorial 1\%/2, j30/4/2009, p.16); y "Despropósitos ante la gripe" (El País, editorial 2\%/2, x06/05/2009, p.26) en: http://elpais.com/diario/2009/05/06/opinion/1241560802_850215.html, recuperado el 21 de febrero de 2014.

4 Cfr. “¿Qué quieren de nosotros?”, Editorial de El Diario de Juárez, 19/09/2010. 
dismo profesional alternativo- resta saber con sistematicidad, qué géneros han sido afectados, y dimensionar los desafíos que los de opinión enfrentan.

Por su parte, es relevante comparar el estado del periodismo de opinión en blogs, en la línea explorada por Colussi, quien sostiene:

"Desde el punto de vista de la economía del trabajo, el movimiento de adaptación de los periodistas al formato blog consiste en una práctica y en un proceso a fin de proteger la ocupación" (Lowrey, 2006). También muchos profesionales creen que la bitácora aumenta su trabajo, sobre todo, cuando se trata de blogs de redacción. Otros ven a los blogs como un antídoto contra la mercantilización que silencia las voces de medios de comunicación independientes (Singer, 2005). También hemos identificado periodistas que viven profesionalmente del periodismo que practican en el blog, como es el caso de los periodistas que mantienen las siguientes bitácoras: Blog do Noblat, Blog de José Roberto de Toledo y Blog de Josias de Souza" (Colussi, 2014: 206).

Si las opiniones publicadas en la prensa periódica sobre las formas de la violencia de Estado -o de la legalidad paralela de la delincuencia organizada- pudieran ser analizadas, en lo general, atribuyendo al periodista alguna responsabilidad dentro de su esfera pública; para la docencia o la investigación, ello implica posicionarse sobre las características de dichos actores y los escenarios compartidos. Es decir que se comprometen éstas, al identificar el contexto a juzgar sobre quién es "responsable", por qué y de qué; pues al no hacerlo -como sucede, de hecho-, pueden normalizarse y propagarse socialmente los rechazos y descalificaciones a contenidos y prácticas periodísticas.

De forma similar, más allá de hallazgos axiológicos en la opinión instituida en referente social, en el conocimiento de las estructuras discursivas del género hay elementos de valor heurístico y epistémico rescatables. En el caso de la "guerra" mencionada junto con la epidemia acontecida, interesa que se busque identificar los argumentos y pruebas, que reflejen los tonos habituales de periódicos, secciones o artículos, ante una mayor complejidad en la información y el sistema mediático. Por ejemplo, con el tono de moderación, de forma tal que, sin llegar al aburrimiento, evite el recurso al morbo.

En otras palabras, la propuesta de una academia comprometida con la formación de profesionales del periodismo responsables, pretende articular sus prioridades con los principios o criterios que regulan las opiniones de una cabecera. Y de ahí a las formas o estructuras que, con la intención de ser persuasivas, apelarán a valores -como la prudencia-, a la vez que a ser pertinentes frente a la actualidad.

\section{La argumentación como acto deóntico de sentido}

A condición de compartir la idea de que en los proyectos de estudios en argumentación periodística, en contextos como el latino- o el iberoamericano, el énfasis final no puede diferir de la creación de sentido -humanitario inclusive y cuando menos comunitario-, se admite que su institucionalidad demanda mayores resultados en la investigación, programas docentes y (en general) productos “tangibles". Además, la acreditación del campo de la opinión como disciplina viene dada por los valores que los profesionales asociados a dicha propuesta cognoscitiva reconocen y manifiestan. 
Si bien es ella una tarea compleja, aún por explorar, existe además una dicotomía entre la visión de un esfuerzo colectivo, y el consumo privado que supone avalar el mérito autoral, o dar credibilidad, como actos personales. Se podría incluso sostener que su discusión académica ha sido injustamente soslayada. Pero otro reto que ahora precisamente emerge, consiste en observar la transformación de las narrativas de opinión -incluida la del ensayo (Rodríguez, 2004)-, y qué condiciones de método y epistémicas se generan: si son distintas a las que prevalecen en mediaciones múltiples, tanto en el ámbito formal de la educación superior, como en los "informales"; así como las condiciones axiológicas que justifiquen una deontología del periodismo con sustrato empírico 5 .

En este sentido, también en la ruta iniciada sobre del tratamiento editorial que en diarios de España se le dio a temas como el narcotráfico en México, se buscó determinar qué rasgos caracterizan a las pruebas retóricas, en la muestra más amplia de columnas, artículos de opinión, editoriales y análisis político-sociales ${ }^{6}$. El análisis de Magaña (2013) abarcó un momento de mutación significativo, en el que en Madrid coexistían en la prensa diarios "híbridos" (digitales-impresos) gratuitos ${ }^{7}$, la "última" nueva cabecera impresa ${ }^{8}, \mathrm{y}$ junto a ellos los hasta entonces de "gran tirada". Se siguieron primero las nociones de "argumentación" de Weston ${ }^{10}$, un marco de investigación especializado en estudios de la retórica del discurso de la opinión periodística española, junto los análisis de artículos de León Gross (1996), y sobre todo los modelos de Santamaría y Casals (2000) y Casals (2003: 76; 2005: 174 y ss. $)^{11}$. Dicho marco, también ha servido de "estado de la cuestión" de un saber legitimado en la teoría y la experimentación, a la vez que representa una plataforma imprescindible para el desarrollo del periodismo contemporáneo.

A manera de resumen de sus planteamientos se resalta que:

- La presencia de columnas editoriales y de opinión "regulares" sigue siendo un indicador fundamental para medir la credibilidad de las líneas editoriales, identificar su pluralidad, congruencia, o la génesis de relaciones comunicativas de autores y/o cabeceras con la ciudadanía lectora.

- Cuando en las noticias se acotan la presencia de gestos de discriminación, extremismo ideológico, prejuicios o estereotipos ligados a ellos, existe un indicio

5 En contra del empirismo ingenuo véase lo dicho por Rubén Jara, citado en Fuentes N. (1991: 103-4); y Habermas (2002: 43 y ss.).

6 En dicho trabajo se partió del carácter autoral (ethos) y sus valores ilustrados; las otras "pruebas clásicas" del discurso retórico (pathos y logos) (Aristóteles, 2003) son señaladas en el corpus (Magaña, 2013).

7 Fue el caso de 20 minutos, en ese momento un medio emergente.

8 Caso de Público.

9 Como El País o $A B C$ en donde, en meses posteriores, se despidió a numerosos profesionales como una aludida secuela de la crisis económica más general.

${ }^{10}$ Para quien argumentar es "ofrecer un conjunto de razones o de pruebas en apoyo de una conclusión" (Weston, 2002: 13).

${ }^{11}$ Sus varios aportes complementan a otras obras, particularmente las originadas desde la Lingüística (Dijk, 1997: 26; Gutiérrez, 1989), o la Filosofía (Habermas, 2002). 
de que una "autorregulación" periodística opera eficazmente a nivel de cobertura. Mientras que ello puede facilitar que en las opiniones se aprecien las formas de convivencia y el valor de la civilidad (Reyes, 1960; Abril, 1987; Keane, 2004) $)^{12}$.

- Se planteó el desafío de construir muestras "significativas" epistémica y axiológicamente, que no resultaran sesgadas ("a modo") desde lo que se supuso encontrar o se quiso mostrar ${ }^{13}$. Luego, al formar un corpus con los textos y quedar las categorías y procesos dispuestos para su interpretación, en la presentación de resultados contrastables y su ponderación, se justificó la estrategia de método desplegada. En estos términos, se confirmó que la conjunción del carácter persuasivo de los textos de opinión y el conocimiento del contexto sobre tales materiales, valida la pertinencia de los análisis retóricos y argumentativos.

La explicación así propuesta del sentido en la prensa de opinión contemporánea incluye entonces un estudio de la argumentación como práctica histórica; la cual a su vez se forma y enriquece mediante debates sociales precisos, esto es: la historia de la prensa se hace a partir de dichos debates y, viceversa, dichos debates son producto de la historia ${ }^{14}$. En ese sentido y en un ámbito que abarca de la libertad de expresión, a la lucha ciudadana por la sociedad democrática, alimentando una conciencia de la historicidad propia, se reconoce la trascendencia histórica de la Ilustración ${ }^{15}$.

De tal forma que, el análisis argumental del periodismo como creador de sentido, al ser enfocado desde la investigación sistemática, permitiría desarrollar áreas particulares de esta actividad, como son descritas a continuación:

a) las líneas editoriales: caracterizadas por un contenido, en apariencia menos polarizado ideológicamente, pero más rebuscado -cuando no confuso- en su orientación sociopolítica, y que implica también a sus regulaciones o compromisos deónticos.

${ }^{12}$ Este hecho es más notorio aún cuando las comunidades interpretativas cuentan con herramientas de participación funcionales como en Facebook. Como se verá más adelante (“4”) ese valor se inscribe en la línea de Aristóteles (2008). Para una "delimitación de conceptos éticos y comunicativos" cfr. Casals (2005: 323). Por otra parte, los cálculos y estrategias pragmáticas de los diarios -reflejados desde sus titulares y hasta en sus estigmas, como en el "tratamiento del delito"- se analizan especialmente en T. van Dijk (2003: 152).

${ }^{13}$ Para ello se ha empleado la llamada "teoría fundamentada" (grounded theory) pues tanto permite los diseños metodológicos para tales abordajes, como armoniza con un recurso central en investigaciones cuantitativas como es la estadística (Orozco, 1997; Valles, 2000).

${ }^{14}$ Por ello la opinión pública, en general, ha sido considerada desde sus inicios también un factor de "universalidad": Tortarolo (1998: 238); Feyel (1998: 266).

${ }^{15}$ Se suscribe con Nazario González una bienvenida al historicismo "...mientras se atenga a la veracidad de los datos y al rigor del proceso lógico que los encadene" (González, 1998: 19); y quien coloca a los textos de Montesquieu, Voltaire, Beccaria, Condorcet, Hume, Rousseau como "inmediatos precursores" de las "primeras declaraciones" de Derechos junto a otros "representantes en toda la Europa Occidental". 
b) Las actualizaciones tecnológicas: dominadas por el soporte multimediático y la orientación al consumo mercantil global; así como por el establecimiento en las relaciones laborales de un productivismo, símbolo de los valores más nuevos y estimados, como eje para llegar a contenidos multiplataforma.

c) la estructura empresarial: condicionada por un modelo de corporativismo "recargado" hacia las élites gobernantes, en donde los compromisos financieros y "planes de negocio" determinan los contenidos.

En esta dirección si en los estudios que se proponen ampliar se evidencia la necesidad de elaborar o hacer efectivos los principios deónticos de una cabecera, en consonancia con generar y sostener la adhesión de una audiencia, se estará en condiciones de observar cómo, además de otorgarle prestigio a aquélla, se refuerza también su identidad. Esta quizá sea la meta más ambiciosa de la formación profesional en el campo comunicativo; así mismo, es desde la aplicación de la ética y la retórica contemporáneas que surge un abordaje, alternativo y complementario, al de cierta sociología que, de manera aislada, estudia a quienes dirigen los medios o la sociedad.

Entonces se vincularían las observaciones sobre el o los valor(es) que se descubren en los contenidos, en el contexto de producción e investigación de regiones de habla hispana. Una vez en ello, las respuestas que este campo científico aporte tendrían que asumir que su estrategia habrá de refinarse, pues el rastro antiguo en las nuevas formas de dominio cultural y dependencia (Thompson, 1998: 121) “...es sólo el más reciente de una serie de encuentros culturales" que marcan un patrón de subyugación complejo (ibíd.: 226).

Esta búsqueda de sentido entiende los derechos a la libre información y opinión en sus cambiantes formas según regiones geopolíticas, así como a las mismas políticas de comunicación, líneas editoriales y hábitos informativos particulares. Con ello se buscan garantías -en última instancia- como son el prever riesgos, al intervenir o denunciar abusos de poder que atentan contra periodistas y escritores.

Como se ha dicho, se supone que existe el fermento para el descubrimiento o desarrollo de nuevas o mejores líneas de trabajo en deontología; pero además, que se puede trabajar simultáneamente en la (re)producción académica de estos saberes, mientras se contribuya con la (auto)regulación de los medios. Ese campo social de investigación sería una interconexión con "marcos de sentido" (Giddens, 1991: 310): ya el de los discursos científicos, ya el de las estructuras narrativas de diarios, secciones en el periodismo, y las retóricas de géneros y estilos de opinión. Así que aunque se asuma la búsqueda de consenso en las comunidades doctas como el fin óptimo, la necesidad de recordar el "compromiso" que se tiene al interior de ellas no es exclusivo, pues: "el supuesto de que la ciencia debe su carácter racional, así como su enorme éxito, a la aplicación de un método universal deja de ser un supuesto hegemónico" (Pérez R., 1995: 172; 192 y ss.; Álvarez, 1995).

Por su parte, es posible que con la crítica a la institución del conocimiento como poder legitimado (o saber instituido) se facilite la interdisciplinariedad que los campos de la comunicación y el periodismo requieren para renovarse. Así podría ocurrir con una propuesta de lectura histórica de Nietzsche -el llamado "perspectivismo 
nietzscheano"- que “...incorpora las dimensiones biológica, pragmática y semiótica del sentido vital, e intenta llegar al fondo de la capacidad interpretadora de los individuos humanos" (Conill, 2001: 95). Con ésta habría un acercamiento diferente al universalismo de los ilustrados, aunque habría que mirarlo detenidamente después.

\section{Crisis y oportunidad en el modelo hegemónico mexicano de comunicación pe- riodística}

Tal y como se ha mostrado prevaleciente en la época "neoliberal" mexicana (Crovi, 2013), con el "liberalismo social" del PRI ${ }^{16}$, y con su contraparte conservadora del $\mathrm{PAN}^{17}$, se conoce que este modelo hegemónico no ha favorecido la integración de minorías indígenas, culturales, o las expectativas de prosperidad en la mayoría social las clases medias y bajas- del país. Por ello, a la violencia que en la región acecha y pone en riesgo la profesión periodística conviene enmarcarla también, siempre que no se olvide el compromiso con un cambio positivo, en un "largo plazo" (Braudel, 1986). Y esa dimensión es la de la crisis de un sistema capitalista que, a nivel doméstico, no bien acaba de cuestionar a los monopolios en telecomunicaciones, ya se retracta y opera política y jurídicamente para atenuar su falta de arrastre social. Por tanto se parte de tener cuidado cuando de oportunidades se habla.

En el caso de la teoría política de la comunicación, resulta de vital importancia la ideal de un modelo "liberal" y de "pluralismo" que Martín Barbero adjudicó a la prensa y, sobre todo, a la mediación de la radio (Martín Barbero, 2003: 244-250). De forma parecida es deseable programar, ahondar en y distinguir ideas como la de "modernidad", con Francisco Arenas Dolz -como lo hiciera Javier Muguerza a partir de Kant-; pues él reconoce la influencia de los deseos e intenciones en la lucha democrática y la deliberación (Arenas, 2008), a partir de consignas como el "sapere aude" la cual retoma su sentido historiosófico en la medida en que se documenta empíricamente el devenir de las ideas "absolutistas" en el debate público, y se obra en consecuencia.

Con la aproximación al pensamiento antiguo de José Luis Ramírez se busca además superar los temores sobre estudios como los clásicos y hermenéuticos (o los humanísticos en general), lo que implica volver al logos:

"Logos como racionalidad práctica, fundamento de la sociedad humana [...] concebido como facultad de dilucidar lo bueno y lo malo, lo útil y lo inútil, discernimiento que está a la base, como bien dice Aristóteles, de la organización de nuestra vida social y familiar. Aparecen [...] los tres elementos de la antropología aristotélica: el elemento ético, el elemento retórico y el elemento social o político" (Ramírez, 2003: 220-21).

Considerando pues que el periodismo es un discurso del "sistema social", así como una práctica histórica y situada, conviene re-aprehender las representaciones de la

${ }^{16}$ Como en los regímenes de Carlos Salinas de Gortari (1988-1994) y Ernesto Zedillo (19942000).

${ }^{17}$ En el período en la presidencia de la República del Partido Acción Nacional (PAN) (20002012): regímenes de Vicente Fox y Felipe Calderón. 
identidad periodística y su alteridad en los contextos de las crisis -global y de cada Estado nacional-, ya que sólo así se pone de manifiesto al subsistema informativo, haciéndolo inteligible.

También en este sentido cobra importancia la filosofía política de Norberto Bobbio, quien sostuvo una idea de corporeidad no-política de las deliberaciones colectivas:

"El proceso de ampliación de la democracia en la sociedad contemporánea [se presenta] sobre todo, mediante la extensión de la democratización entendida como institución y ejercicio de procedimientos que permiten la participación de los interesados en las deliberaciones de un cuerpo colectivo, en cuerpos diferentes de los políticos" (Bobbio, 1991: 218).

Desde Hegel (1975), Marx (1968), Gramsci (1986) y hasta Sánchez Vázquez (1968), Ortega (2004), Casals (2005: 107) o Reguillo (2005), se han suscitado importantes contribuciones teóricas a partir de una concepción de "polis" que deriva de una fragmentación -pérdida de legitimidad, soberanía o poder- del Estado como entidad "real y racional". Lo cual es destacado aun cuando, en la actual realidad de los partidos mexicanos, los de carácter nacional se hayan sumado a un bloque con el poder del gobierno. El oficialismo que esa oposición ha dejado ver no obsta para que la sociedad dé muestras de usos distintos de la comunicación y voluntad de cambios. Por ello es deseable que más actores académicos locales se involucren en esta u otras deliberaciones, así como que el resto de la comunidad internacional asuma su responsabilidad por lo que ocurre en la "sociedad global".

Como se ha dicho ya, la fuerza de las contradictorias circunstancias en el periodismo nacional afectan, así mismo, la estructura de la información internacional. En cualquier caso, un abordaje positivo incluirá una epistemología y axiología de cuño distinto; la cual se refiere a la posibilidad de insertar los últimos avances de la investigación en programas institucionales ya existentes, sin perder de vista los impactos reales entre quienes aspiran a la "profesionalidad" (Real et al., 2007: 202 y sigs.). Con el fin de reivindicar las enseñanzas, tanto como de encontrar canales adecuados para los géneros marginados, la pareja de saberes y valores que así se busca, tendrá entonces que trazar un puente que entrelace: la diversidad de las regiones, la fragmentación de las audiencias o las preferencias múltiples por medios y contenidos.

Finalmente, a la esfera pública y mediática se les podría representar desde la apropiación que hagan de valores como: la resistencia sincrética a la inequidad o al avasallamiento homogeneizante; o el combate al planteamiento maniqueo entre dogmatismo universalista y relativismo particularista, por ejemplo: mediante la crítica de unas "prácticas técnico-burocráticas (por ejemplo, la mercadotecnia, la demoscopia, la «ingeniería política»)" cuando se pretenden transformar en "criterios" de "argumentación", bajo condiciones desigualitarias en el régimen de información llamado "posmoderno" (Abril, 1987: 63).

\section{Conclusiones}

Reconocer valores como la independencia periodística, o el pluralismo genera condiciones favorables para la integración de voces para la deliberación comunitaria. Ello se propicia cuando, desde la docencia y la investigación, se aporta "consistencia" a la 
profesión periodística; de forma tal que géneros como los de opinión generen aprecio y simpatía -lo cual ya ha ocurrido, como cuando la separación artificial entre un periodismo "purista", frente a uno "sensacionalista" ha sido superada desde el trabajo empírico, teórico y metódico ${ }^{18}$.

La utilización del análisis retórico y de la argumentación, más que del "análisis de contenido" se justifica, en última instancia, desde el empleo de unas estrategias de acceso, levantamiento y análisis de información; a las que también he llamado: una etnohemerográfica y otra de lectura comprensiva (Magaña, 2013). Además, por propiciar el diálogo constructivo que se establece con el discurso "posdisciplinario" (Mattelart, 1995; Reguillo, 2005), y participar en el diálogo constructivo que se establece entre metodologías "cuantitativas" o "cualitativas" (Jensen, 2002).

\section{Referencias bibliográficas}

ABRIL, Gonzalo (1987): "Complicidad, polifonía y ética del discurso". Revista de Occidente, $\mathrm{n}^{\mathrm{o}} 9$ (diciembre). Madrid, pp.77-91.

ÁLVAREZ, Sebastián (1995): "Racionalidad y método científico", en OLIVÉ, León (ed.): Racionalidad epistémica. Madrid, Ed. Trotta y C.S.I.C. Enciclopedia Iberoamericana de Filosofía, Tomo 9, pp.147-169.

ARENAS, Francisco (2008): "Gramáticas de la deliberación", en MORATALLA, Agustín D. y LISÓN, J. Francisco (eds.): Ética, ciudadanía y desarrollo. Valencia, Patronat Sud-Nord y Universidad de Valencia, pp.151-177.

ARISTÓTELES (2003): Retórica. [Edición y traducción: Antonio Tovar] Madrid, Centro de Estudios Políticos y Constitucionales.

ARISTÓTELES (2008): Ética Nicomaquea. [trad. Julio Pallí Bonet] Barcelona, Círculo de Lectores - Gredos.

BOBBIO, Norberto (1991): "Democracia y dictadura". Estado, gobierno y sociedad. Para una teoría general de la política. [trad. José F. Fernández] México, F.C.E., pp. 188-233.

BRAUDEL, Fernand (1986): La Historia y las Ciencias Sociales. [trad. Josefina Gómez] Madrid, Alianza.

CASALS, María Jesús (2003): “Juan José Millás: La realidad como ficción y la ficción como realidad (o cómo rebelarse contra los amos de lo real y del lenguaje). Análisis de Juan José Millás, columnista de El País". Estudios sobre el mensaje periodístico, $\mathrm{n}^{\circ}$ 9. Madrid, Servicio de Publicaciones de la Universidad Complutense, pp. 63-124.

18 Tómese por ejemplo, la descripción del "unomásuno", rotativo de los años 80 en México, que lo retrata como órgano de quienes serían una generación "...de individuos apasionados, sobreemotivos, románticos, honorables, transgresivos, insobornables, iconoclastas, perseverantes, que transitan del nihilismo al dogma" (Krauze, 1983: 157). 
CASALS, María Jesús (2005): Periodismo y sentido de la realidad. Teoría y análisis de la narrativa periodistica. Madrid, Fragua.

COLUSSI, Juliana (2014): El blog periodístico como mini diario digital: análisis de la narrativa, redacción y criterios profesionales en los blogs periodísticos políticos integrados en la web de periódicos de Brasil y España (2010-2012). Tesis doctoral. Madrid, Universidad Complutense.

CONILL, Jesús (2001²): El poder de la mentira. Nietzsche y la política de la transvaloración. Madrid, Tecnos.

CROVI, Delia (2013): "Industrias culturales en México. Estrategias y políticas gubernamentales", en CROVI, Delia (coord.): Industrias culturales en México. Reflexiones para actualizar el debate. México D.F., Tintable - UNAM; pp. 13-39.

DIJK, Teun A. Van (1997): Racismo y análisis crítico de los medios [trad. Montserrat Basté]. Barcelona, Paidós.

DIJK, Teun A. Van (2003): "La multidisciplinariedad del análisis crítico del discurso: un alegato en favor de la diversidad", en WODAK, Ruth y Michael MEYER: Métodos de análisis crítico del discurso. Barcelona, Gedisa, pp. 143-177.

FEYEL, Gilles (1998): "El periódico", en FERRONE, Vicenzo y ROCHE, Daniel (eds.): Diccionario histórico de la ilustración. Madrid, Alianza, pp. 261-268.

FUENTES, Raúl (2000): Educación y telemática. Buenos Aires, Norma.

GIDDENS, Anthony (1991): La constitución de la sociedad. Bases para la teoría de la estructuración. Buenos Aires, Amorrurtu.

GONZÁLEZ, Nazario (1998): Los Derechos Humanos en la Historia. Bellaterra (Barcelona), Edicions Universitat de Barcelona - Universitat Autònoma de Barcelona.

GRAMSCI, Antonio (1986²): "Algunos problemas para el estudio de la filosofía de la praxis", en El materialismo histórico y la filosofia de B. Croce [trad. I. Flaumbaun] México, Juan Pablos, pp. 80-121.

GUTIÉRREZ, Silvia (1989): "La argumentación", en Argumentos, estudios críticos de la sociedad, n.8, diciembre. México, Universidad Autónoma Metropolitana Xochimilco, pp. 7-20.

HABERMAS, Jürgen (2002): Teoría de la acción comunicativa. México, Taurus (2 vols.).

HEGEL, George W. F. (1975): Filosofia del Derecho. México D.F., UNAM.

JENSEN, Klaus B. (ed., 2002): "The qualitative research process", en JENSEN, Klaus (ed.). A Handbook of Media and Communication Research: Qualitative and Quantitative Methodologies. London, Routledge, pp. 235-253.

KEANE, John (2004): "Journalism and democracy across borders", en: http://johnkeane.net/22/topics-of-interest/journalism-and-democracy-across-borders [Consulta: 1 de julio de 2014].

KRAUZE, Enrique (1983): Caras de la historia. México, Joaquín Mortiz. 
LEÓN GROSS, Teodoro (1996): El artículo de opinión. Introducción a la historia y la teoría del articulismo español. Barcelona, Ariel.

MAGAÑA HERNÁNDEZ, Gilberto (2013): Ethos ilustrado y metáfora educativa. La opinión periodística española y su retórica sobre México. Tesis doctoral. Madrid, Universidad Complutense.

MARTÍN Barbero, Jesús (2003): De los medios a las mediaciones. Bogotá, Convenio Andrés Bello.

MARX, Karl (1968): Crítica de la filosofia del Estado de Hegel [trad. Antonio Encinares] México D.F., Ed. Grijalbo.

MATTELART, Armand (1995): La invención de la comunicación [trad. Gilles Multigner] México, Siglo XXI.

OROZCO, Guillermo (1997): "Tendencias generales en la investigación de los medios. Un encuentro pendiente", en Comunicación y Sociedad, $\mathrm{n}^{\circ}$ 30. Guadalajara (México), Universidad de Guadalajara, pp. 101-125.

ORTEGA, Patricia (2004): "El espacio público en las sociedades contemporáneas", en VVAA: Anuario de investigación 2003. México, UAM-X, pp. 194-205.

PÉREZ, Ana Rosa (1995): "Racionalidad y desarrollo científico", en OLIVÉ, León (ed.): "Racionalidad epistémica". Enciclopedia Iberoamericana de Filosofía, tomo 9. Madrid, Trotta y C.S.I.C., pp. 171-201.

RAMÍREZ, José Luis (2003): “Tópica de la responsabilidad. Reivindicación de la retórica para la ciudadanía moderna", en CONILL, Jesús y CROCKER, David A. (eds.): Republicanismo y educación cívica. Granada, Comares, pp. 219-242.

REAL, Elena; AGUDÍEZ, Pinar; y PRÍNCIPE, Sergio (2007): "Periodismo ciudadano versus periodismo profesional: ¿somos todos periodistas?". Estudios sobre el Mensaje Periodístico, núm. 13. Madrid, Servicio de Publicaciones de la Universidad Complutense, pp. 189-212.

REGUILLO, Rossana (2005): Horizontes fragmentados; comunicación, cultura, pospolítica. El (des)orden global y sus figuras. Guadalajara, México, ITESO.

REYES, Alfonso (1960): "La Antigua retórica”, en Obras completas, tomo XIII. México, F.C.E.

RODRÍGUEZ, Fernando (2004): “El ensayo y lo sopesado", en: http://www.ensayistas.org/critica/ensayo/rodriguez.htm\#_ftnref1 [Consulta: 9 de febrero de 2009]

SÁNCHEZ, Adolfo (1968): "Marx y su crítica de la filosofía política de Hegel". Prólogo a MARX, Karl: Crítica de la filosofía del Estado de Hegel [trad. Antonio Encinares]. México D.F., Grijalbo, pp. 5-10.

SANTAMARÍA, Luisa y CASALS, María J. (2000): La opinión periodística. Argumentos y géneros para la persuasión. Madrid, Fragua.

THOMPSON, John B. (1998): Los media y la modernidad. Barcelona, Paidós.

TORTAROLO, Edoardo (1998): “Opinión pública”; en FERRONE, Vicenzo y ROCHE, Daniel (eds.): Diccionario histórico de la ilustración. Madrid, Alianza. 
VALLES, Manuel (20003): "La grounded theory y el análisis cualitativo asistido por ordenador", en GARCÍA, Manuel (ed.): El análisis de la realidad social. Métodos y técnicas de investigación. Madrid, Alianza, pp. 575 - 603.

WESTON, Anthony (2002): Las claves de la argumentación [trad. Jorge F. Malem]. Barcelona, Ariel. 